\title{
Pneumopericardium in a Newborn with Respiratory Distress and COVID-19
}

\author{
Pandih Kahayana Harancang ${ }^{1}$, Jonathan Edbert Afandy ${ }^{1}$, Lilia Dewiyanti ${ }^{1}$ D, Zuhriah Hidajati ${ }^{1}$, Neni Sumarni ${ }^{1}$, \\ Adriana Lukmasari ${ }^{1}$ iD, Cipta Pramana ${ }^{2 *}$ (D) \\ ${ }^{1}$ Department of Pediatrics, Faculty of Medicine, Tarumanagara University, KRMT Wongsonegoro General Hospital Semarang, \\ Jakarta, Indonesia; ${ }^{2}$ Department of Obstetrics and Gynecology, Faculty of Medicine, Tarumanagara University, KRMT \\ Wongsonegoro General Hospital Semarang, Jakarta, Indonesia
}

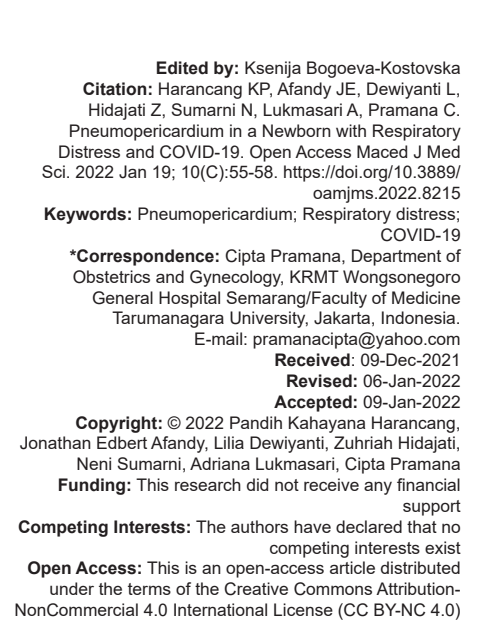

\section{Abstract}

BACKGROUND: Pneumopericardium (PPC) is one of the rarest pulmonary air leak syndromes, but the incidence is the highest in the neonatal period. Risk factors include premature infants with respiratory distress (RD) syndrome receiving active resuscitation, meconium aspiration syndrome, and aggressive mechanical ventilation. Several cases have also been reported related to COVID-19.

CASE PRESENTATION: We report a case of a female newborn with a birth weight of 3300 grams a COVID-19 confirmed 35-year-old G3P2A0 mother. The baby was not crying at born and the amniotic fluid was stained green. The baby experienced RD and was intubated. A babygram was performed at the age of $5 \mathrm{~h}$ with the impression of a too deep endotracheal tube, neonatal pneumonia, and PPC. COVID-19 RT-PCR examination of the baby was positive. There were no signs of cardiac tamponade, so it was decided to take conservative and supportive management.

CONCLUSION: Resolution of PPC was found on repeated babygram $26 \mathrm{~h}$ later. The baby was then discharged after 19 days of treatment.

\section{Introduction}

Pneumopericardium (PPC) is a condition where air collects in the pericardium. Its one of the rarest pulmonary air leak syndromes, but the incidence is the highest in the neonatal period [1], [2]. Risk factors for PPC include premature infants with respiratory distress (RD) syndrome, receiving active resuscitation, meconium aspiration syndrome (MAS), and aggressive mechanical ventilation (MV). If not treated properly, PPC can lead to catastrophic complications of cardiac tamponade, resulting in significant morbidity and mortality [3]. Treatments include needle pericardiocentesis, continuous pericardial drainage, and in certain conditions conservative and supportive approach could be an option [4], [5].

Only $3 \%$ of neonates born to mothers with COVID-19 had a positive PCR examination. The clinical presentation of neonates with COVID-19 varies widely, from asymptomatic to critical condition. Among symptomatic neonates, the most common clinical presentations were RD (40\%), fever (32\%), and feeding intolerance (24\%) [6]. At the KRMT Wongsonegoro Hospital in Semarang, Indonesia, one case of a premature baby with COVID-19 has been reported with severe respiratory failure [7]. Several cases of PPC also have been reported to be related to COVID-19. [8], [9], [10].

On this occasion, we present a case of a female newborn with RD and COVID-19 who experienced spontaneous resolution of PPC with conservative therapy.

\section{Case Presentation}

A female newborn was delivered at 41 weeks, with a birth weight of 3300 grams from a 35-yearold G3P2A0 mother. The mother was confirmed for COVID-19. The baby was born by cesarean section with indications of prolonged labor. The baby was not crying at born and the amniotic fluid was stained green. 
Neonatal resuscitation was performed, dark greenish fluid was obtained from mouth and nose suction. Positive pressure ventilation (PPV) is performed because of inadequate breathing and the baby looks cyanotic. The general condition looks weak, whimpering. APGAR scores were 5-5-7 at 1, 5, and $10 \mathrm{~min}$. The baby was sent to the Isolation NICU and given non-invasive ventilation oxygen therapy with $40 \%$ fraction of inspired oxygen $\left(\mathrm{FiO}_{2}\right)$, positive end-expiratory pressure (PEEP) $6 \mathrm{cmH}_{2} \mathrm{O}$, peak inspiratory pressure (PIP) $12 \mathrm{cmH}_{2} \mathrm{O}$.

One hour after birth, the baby is desaturated with $\mathrm{SatO}_{2} 40 \%$ on PPV, there was chest retraction, nostrils breath, cold extremities, and capillary refill time $>2 \mathrm{~s}$. It was decided to intubate with size 3.5 uncuffed endotracheal tube (ETT), $9 \mathrm{~cm}$ deep, attached to MV with pressure control mode, inspiratory pressure (Pinsp) 13 $\mathrm{CmH}_{2} \mathrm{O}, \mathrm{PEEP} 82 \mathrm{O}$, respiratory rate (RR) 40, $\mathrm{FiO}_{2} 100 \%$. A no. Eight orogastric tube was also installed, there is green residue. An umbilical catheter was attached to a depth of $7 \mathrm{~cm}$. After the ETT was installed, heart rate (HR) was 110-160 beats/min, RR 75-90 times/min, SatO 77-90\%. Physical examination reveals marked RD. Cardiac examination revealed normal heart sounds with no murmurs or additional sounds.

A babygram was performed at the age of $5 \mathrm{~h}$, the impression was too deep ETT, features of neonatal pneumonia, and PPC (Figure 1). Clinically, there were no signs of cardiac tamponade and hemodynamically

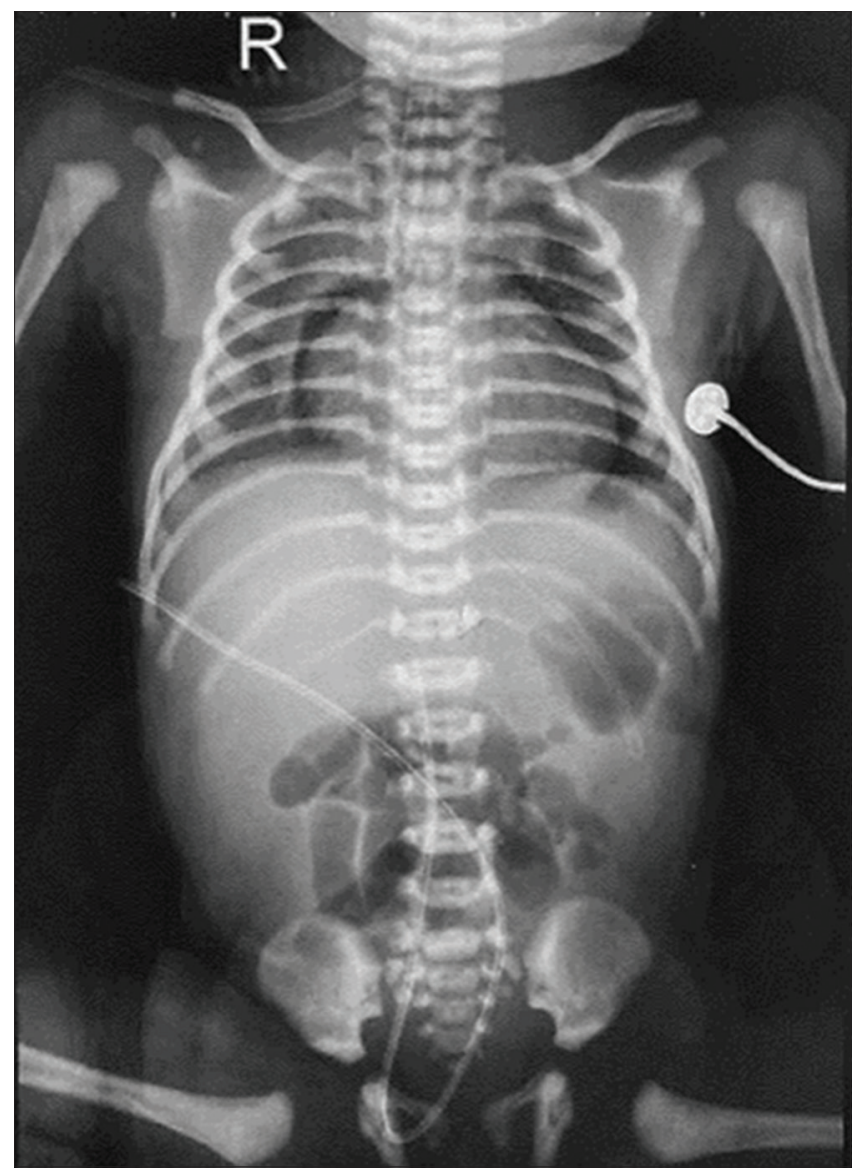

Figure 1: Babygram showed too deep endotracheal tube, pneumonia, and Pneumopericardium stable. The ETT was withdrawn for $1 \mathrm{~cm}$, the MV setting was maintained. After withdrawal of the ETT, there was clinical improvement with vital signs HR 130-150 beats/ min, RR 60-80 times/min, SatO 2 96-99\%.

On the $2^{\text {nd }}$ day, the results of nasopharyngeal and oropharyngeal swabs for COVID-19 RT-PCR examination were positive. A repeat babygram was performed at $31 \mathrm{~h}$ of age with the impression of neonatal pneumonia and resolution of PPC (Figure 2). The COVID-19 RT-PCR examination was negative on the $6^{\text {th }}$ and $7^{\text {th }}$ days. On the $11^{\text {th }}$ day, echocardiography was performed, the impression of normal cardiac structure was found, there was no PPC.

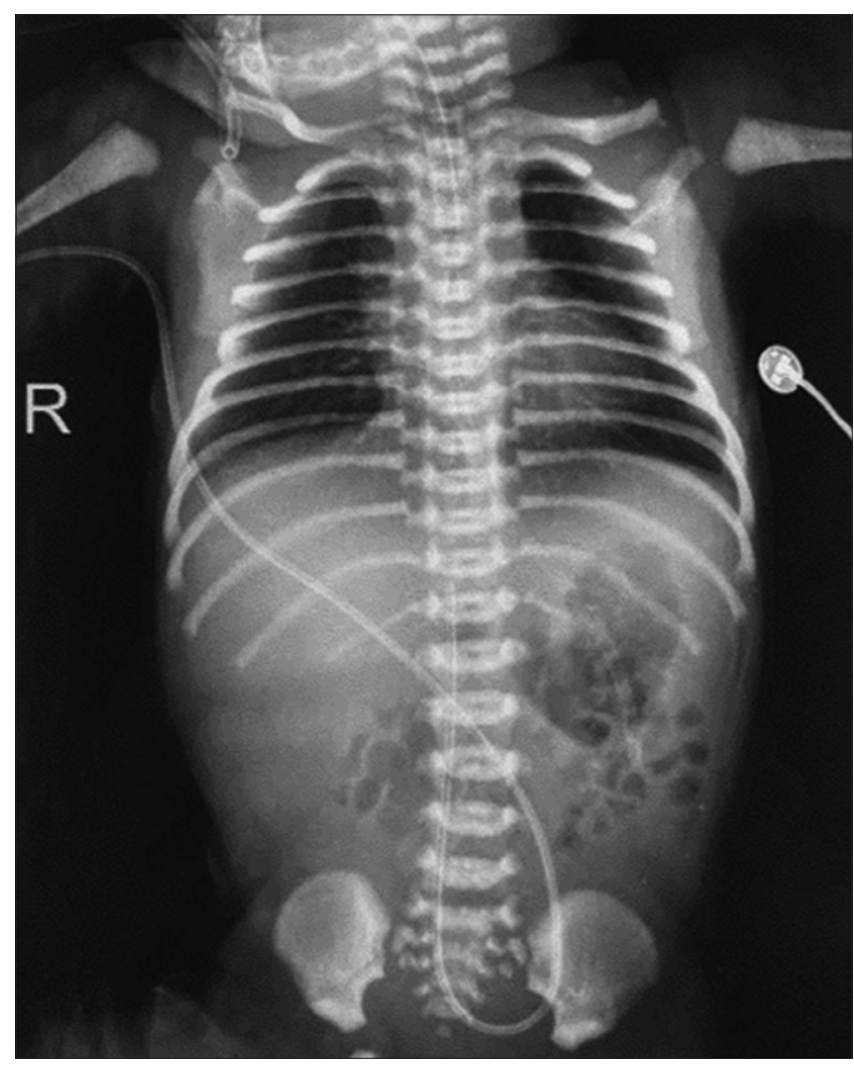

Figure 2: Resolution of Pneumopericardium on repeated babygram 26 h later

On the next clinical course, the baby had shock, sepsis, and ventilator-associated pneumonia. Weaning of oxygen therapy was carried out gradually until breathing with room air on the $14^{\text {th }}$ day. On the $19^{\text {th }}$ day, the baby was discharged.

\section{Discussion}

PPC is categorized into two types according to its pathogenesis. Spontaneous PPC in neonates is associated with pulmonary diseases such as hypoplasia and RD syndrome. Traumatic PPC occurs by pleural-pericardial communication associated with chest trauma and iatrogenic chest injury [1]. 
The pathogenesis of PPC is thought to be due to high bronchoalveolar pressure causing rupture of alveoli and air leakage into the perivascular interstitium of the lung, hilum, and mediastinum, then to the pericardial space on pulmonary vein reflection which is postulated to have an anatomical weakness [3].

Airway obstruction by the meconium plug causes high resistance to airflow and the presence of trapped air. Complete obstruction by meconium can cause atelectasis [10]. When the number of alveoli that can expand during inspiration is reduced, the risk of spontaneous rupture is greater because of overdistention [11], [12]. This is consistent with what happened to our patient where RD was suspected due to MAS and neonatal pneumonia. The diagnosis of MAS can be established based on criteria: there were RD in newborns with meconium-stained amniotic fluid, oxygen demand to maintain saturation above $92 \%$, need for oxygen therapy within $2 \mathrm{~h}$ of life for at least $12 \mathrm{~h}$, and the absence of airway, lung, and heart malformations [11]. Although in our patient the radiological picture did not support the diagnosis of MAS.

The spectrum of PPC can vary from asymptomatic to $\mathrm{RD}$, muffled to absent heart sound, and severe hemodynamic instability [3]. Chest X-ray is the standard diagnostic method with the classic finding in PPC is "halo sign" i.e., air completely surrounds, and limits the heart but does not extend beyond the reflection of the pericardium into the great vessels [13]. When PPC is small, the pericardial air may not surround the heart completely and exist only along a single border called "pericardial line" [14]. In our patient, pericardial air was found and did not extend beyond great vessels consistent with the PPC image. The radiological differential diagnosis is "spinnaker-Sail sign" showing neonatal pneumomediastinum [15].

Regarding the use of MV, a study by Cohen et al. showed that the incidence of PPC was associated with high PIP with a mean of $42 \mathrm{mmHg}$ equivalent to $57 \mathrm{cmH}_{2} \mathrm{O}$ (range 26-60 mmHg or 35-82 $\mathrm{cmH}_{2} \mathrm{O}$ ) [16]. Our patient used a relatively low PIP of $13 \mathrm{cmH}_{2} \mathrm{O}$.

In Burt and Lester's study of 50 patients with PPC, $28 \%$ had an ETT misplacement [14]. Based on the babygram in our patient, it is known that the distal tip's location of ETT is too deep in the thoracal vertebrae III so that it is one of the predispositions for PPC.

Several cases of PPC have been reported in adult COVID-19 patients [8], [9], [10]. The underlying mechanism is suspected that COVID-19 triggers inflammatory dysregulation that causes diffuse damage and alveolar rupturen [9]. SARS-CoV2 infection in our patient may be an additional risk factor for developing PPC.

In asymptomatic cases, a conservative approach and supportive care are the mainstays. $100 \%$ oxygen therapy causing "nitrogen washout" can be used in stable infants but not in newborn
$<32$ weeks of gestational age due to complications of hyperoxia [3], [14]. However, according to the study of Shaireen et al., there was no difference in the resolution time of pneumothorax between neonates receiving high concentration, medium concentration, or room air oxygen therapy. Hence, oxygen therapy should be given based on oxygen saturation targets [17]. In our patient, it was decided to take a conservative approach because there were no signs of cardiac tamponade, $\mathrm{FiO}_{2} 100 \%$ oxygen therapy is maintained to meet the oxygen saturation target. Percutaneous pericardial aspiration may be attempted if hemodynamic instability results from tamponade. Continuous pericardial drainage may be used in recurrent and extensive cases [3], [14].

\section{Conclusion}

PPC is a rare case and usually associated with events that cause alveolar rupture. The diagnosis can be made based on clinical examination and chest $X$-ray. In asymptomatic cases, conservative management may be an option with close observation.

\section{Acknowledgment}

Thank you to the patient's parents for agreeing to have their case published.

\section{References}

1. Tani M, Kanazawa T, Shioji N, Shimizu K, Iwasaki T, Morimatsu H Successful treatment with positive airway pressure ventilation for tension pneumopericardium after pericardiocentesis in a neonate: A case report. JA Clin Rep. 2020;6(1):79. https://doi. org/10.1186/s40981-020-00384-x

PMid:33029685

2. Markovic-Sovtic G, Nikolic T, Sovtic A, Martic J, Rakonjac Z Pulmonary air leak syndrome in term and late preterm neonates. Srp Arh Celok Lek. 2019;147(9-10):578-82.

3. Roychoudhury S, Kaur S, Soraisham AS. Neonata pneumopericardium in a nonventilated term infant: A case report and review of the literature. Case Rep Pediatr. 2017;2017:3149370. https://doi.org/10.1155/2017/3149370 PMid:29430316

4. Kataria-Hale J, Fernandes CJ, Speer ME. Pneumopericardium in the neonate: A case report. Perfusion. 2020;35(4):360-2. https://doi.org/10.1177/0267659119868916 PMid:31416399

5. Satheeshkumar D, Kumaravel K, Karuna C, Hemalatha M, Sampathkumar P. A case of conservatively managed pneumopericardium in a neonate. Pediatr Oncall. 2018;15(4):114. 
6. Barrero-Castillero A, Beam KS, Bernardini LB, Ramos EG, Davenport PE, Duncan AR, et al. COVID-19: Neonatal-perinatal perspectives. J Perinatol. 2021;41(5):940-51. https://doi. org/10.1038/s41372-020-00874-x

PMid:33293665

7. Sumarni N, Dewiyanti L, Kusmanto MH, Pramana C. A case of 2019 novel Coronavirus infection in a preterm infant with severe respiratory failure. Int J Pharm Res. 2020;12(4):1935-8.

8. Sahu KK, Mishra AK, Goldman Y. A rare case of pneumopericardium secondary to COVID-19. Heart Lung. 2020;49(6):679-80. https://doi.org/10.1016/j.hrtlng.2020.08.017 PMid:32861883

9. Li S, Chau E, Ghasem W, Sohn J, Yaghmour B. Air should not be there: A case of pneumomediastinum and pneumopericardium in. Cureus. 2020;12(11):e11696. https://doi.org/10.7759/cureus.11696 PMid:33391929

10. Singh A, Bass J, Lindner DH. Rare complication of pneumomediastinum and pneumopericardium in a patient with COVID-19 pneumonia. Case Rep Pulmonol. 2020;2020:8845256. https://doi.org/10.1155/2020/8845256 PMid:33204564

11. Monfredini C, Cavallin F, Villani PE, Paterlini G, Allais B, Trevisanuto D. Meconium aspiration syndrome: A narrative review. Children. 2021;8(3):230. https://doi.org/10.3390/ children8030230

PMid:33802887

12. Junghaenel S, Sreeram N, Demant A, Vierzig A, Kribs A, Roth B.
Pneumopericardium as a rare complication of continuous positive airway pressure in spontaneously breathing neonates. Klin Pädiatr. 2012;224(1):34-5. https://doi.org/10.1055/s-0031-1298025 PMid:22161563

13. Suryawanshi PB, Klimek J. Preterm neonate with spontaneous pneumopericardium without any other associated air leaks. J Clin Diagn Res. 2014;8(1):181-2. https://doi.org/10.7860/ JCDR/2014/5620.3945

PMid:24596765

14. Burt T, Lester P. Neontal pneumopericardim. Radiology 1982;142(1):81-4. https://doi.org/10.1148/radiology.142.1.7053553 PMid:7053553

15. Vanden Berghe S, Devlies F, Seynaeve P. The spinnaker-sail sign: Neonatal pneumomediastinum. J Belg Soc Radiol. 2018;102(1):51. https://doi.org/10.5334/jbsr.1589

PMid:30155525

16. Cohen DJ, Baumgart S, Stephenson LW. Pneumopericardium in neonates:IsitPEEPorisitPIP?AnnThoracSurg. 1983;35(2):179-83. https://doi.org/10.1016/s0003-4975(10)61457-9 PMid:6337571

17. Shaireen $H$, Rabi $Y$, Metcalfe A, Kamaluddeen $M$, Amin $H$ Akierman $\mathrm{A}$, et al. Impact of oxygen concentration on time to resolution of spontaneous pneumothorax in term infants: A population-based cohort study. BMC Pediatr. 2014;14(1):208. https://doi.org/10.1186/1471-2431-14-208

PMid:25149271 